\title{
Contacto alienígena y Transformers ¿el escenario más probable?*
}

\section{doi: $10.52749 /$ fh.v2i3.1}

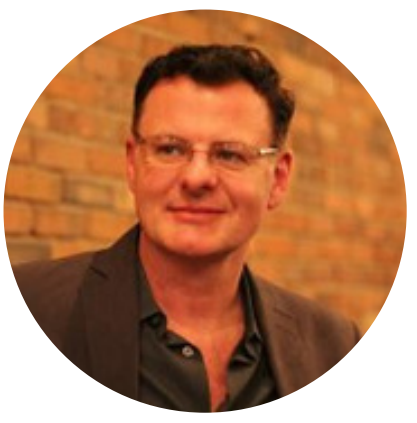

\section{JOHN R. SHOOK}

iD https://orcid.org/0000-0003-2562-9860

John Shook es un filósofo humanista secular, PhD en filosofía por la Universidad de Buffalo. Fue Director de Educación e Investigador Senior en el Center for Inquiry - Transnational en Amherst, NY, e Investigador Asociado en Filosofía en la Universidad de Buffalo, desde 2006. Ha sido profesor de filosofía de la Universidad de Oklahoma del 2000 al 2006. Es autor y editor de más de una docena de libros y co-editor de tres revistas de filosofía.

jrshook@bowiestate.edu

Los poderosos Transformers, involucrados en otro episodio más en el conflicto milenario entre los Autobots y los Decepticons, se encuentran accidentalmente con la Tierra y sus insignificantes habitantes. No tenían idea de que estábamos aquí, no los vimos venir $y$, al llegar, se enmascaran para parecerse a nuestras propias máquinas. Un aterrizaje forzoso; un disfraz rápido. Eso es todo lo que se necesitaría.

\section{Primer contacto}

Es una pregunta asombrosa con muchas respuestas potenciales. ¿Cómo podemos los humanos darnos cuenta de que no estamos solos? El primer contacto ha sido durante mucho tiempo la especialidad de los escritores de ciencia ficción, pero la ciencia real ahora se está poniendo al día. Es cierto que pocas historias de ciencia ficción comienzan como comienza la saga de Transformers.

Una civilización extraterrestre, de formas de vida de inteligencia artificial, tropieza con la Tierra mientras está obsesionada con librar su propia guerra civil. Esta no es una trama típica del género de ciencia ficción. Quizás no sea lo suficientemente romántico o heroico. ¿No preferimos las historias que nos dan crédito a los intrépidos exploradores por penetrar en los acontecimientos de la galaxia? ¿Y no apreciamos más a los extraterrestres, incluso a los cobardes, cuando se ven y piensan como nosotros? Los autores de ciencia ficción conocen un cuento pegadizo cuando escriben uno porque tienen una forma de conocernos muy bien a los humanos.

¿Y los científicos? Bueno, la mayoría de los científicos también parecen preferir algún otro resultado final que la versión de Transformers del Primer Contacto. Esperar a que los extraterrestres nos encuentren no es el tipo de solución tecnológica práctica y proactiva que mantiene a los científicos empleados y ocupados. La ciencia se trata de descubrimiento, ¿verdad? Entonces, ¡salgamos a buscarlos primero! $Y$ dado que los extraterrestres probablemente se parecen mucho a nosotros, al menos en lo que respecta a su vasta inteligencia y curiosidad científica, naturalmente también nos estarían buscando. Y mientras estamos en el tema de la motivación, reflexionan los científicos, infiramos que una civilización superior implica una virtud superior. Si una civilización alienígena avanzada ha sobrevivido durante tanto tiempo, probablemente haya superado los odios y las guerras. ¡Estos extraterrestres son más como ángeles!

\section{Sintonizando}

Ni la ciencia ficción ni los hechos científicos quieren crear un lugar para considerar seriamente el extraño escenario de Transformers. Queremos pensar que podemos encontrarlos primero; o si los extraterrestres nos encuentran, es porque lo estaban intentando. Queremos imaginarnos a los extraterrestres de formas vagamente antropomórficas, que sean raros, pero no demasiado raros. Queremos esperar que las civilizaciones avanzadas sean mucho más avanzadas éticamente y no solo tecnológicamente avanzadas. Nuestro escenario ideal básicamente es el siguiente: los humanos buscan ángeles, los ángeles están felices de ser encontrados, los ángeles ayudan a los humanos. ¿Le suena familiar este argumento (consulte la religión más cercana)?

Nada sobre la trama de Transformers parece intuitivo o satisfactorio. De todos modos, ¿es realmente tan improbable la saga de los Transfor- 
mers?

De hecho, podría resultar ser una de las formas más probables en que finalmente encontremos una civilización alienígena. Dejando a los escritores de ciencia ficción a su imaginación, veamos algunas razones científicas y filosóficas por las que la historia de Transformers puede ser una profecía sabia. Al igual que los propios Transformers, la saga de Transformers es más de lo que parece.

Comencemos con la búsqueda de vida extraterrestre por parte de los científicos. Adelante, invierta cientos de millones de dólares en las antenas parabólicas y supercomputadoras de la más alta tecnología. Analice el ruido aleatorio de los densos brazos cercanos de la Vía Láctea, o de sus pequeños cúmulos de nebulosas, todo lo que quiera. Sí, todos sentimos curiosidad por saber si hay vida ahí fuera. Pero, ¿sabemos realmente de qué se supone que debamos estar atentos?

Tiene sentido suponer que cualquier civilización intergaláctica tendría una tecnología increíblemente avanzada. Tales Poderes tecnológicos avanzados se compararían con los poderes de nuestra civilización, como nuestros Poderes humanos se comparan con los de las hormigas. Entonces, ¿qué tecnología estamos usando para nuestras búsquedas en el espacio? Oh, sí, la Búsqueda de Inteligencia Extraterrestre (SETI), el orgullo de tantos científicos comprometidos con el objetivo de detectar extraterrestres, está usando naturalmente la radio. Sí, radio.

¿Recuerdas la radio? Toda la sensación a finales del siglo XIX. Las vibraciones pulsantes de la radiación electromagnética. Los fotones, esencialmente, fluyen por todo el espacio. Los fotones han existido desde el principio, el Big Bang, hace unos catorce mil millones de años. Incluso el espacio "vacío" ha estado bastante lleno de estas pequeñas cosas enérgicas desde entonces, y los billones y billones de estrellas del universo, y todo lo demás que involucra colisiones de átomos, siguen produciendo más. También se pueden generar y controlar artificialmente con componentes electrónicos muy simples, y eso es lo que Marconi (el inventor de la radio, que más tarde ganó el Premio Nobel de Física en 1909) descubrió cómo hacer. La televisión es solo una versión más elegante de la transmisión de radio, que utiliza el mismo tipo de radiación electromagnética en frecuencias más altas. Dado que la mayoría de las ondas de radio AM y FM son absorbidas por la at- mósfera de la Tierra, la primera visión de los extraterrestres de nosotros podría ser en realidad una transmisión de televisión de 1936 de Adolph Hitler. Ciertamente un motivo de alarma. Pero toda esta información terrenal, lo bueno, lo malo y lo feo, se reduce a corrientes de pequeños fotones.

Los fotones son abundantes, baratos y fáciles de hacer. No es de extrañar, entonces, que los humanos inventaran la radio casi al mismo tiempo que inventamos el automóvil. Ahora hay una gran tecnología que podemos esperar utilizar durante miles de años en el futuro. Oh, no, supongo que no. Si los humanos todavía dependen de los vehículos de combustión interna propulsados por petróleo dentro de diez mil años, esta especie realmente ha chocado contra una pared. ¿Seguiremos usando la radio dentro de diez mil años? Quizás, para las funciones mecánicas más simples. Pero si la radiación electromagnética sigue siendo nuestro medio de comunicación más avanzado durante tanto tiempo, no habremos progresado mucho. Seguramente no nos habremos enfrentado a otros desafíos importantes para la propagación de la especie, como llegar a otros sistemas estelares para la colonización y comunicarse en algo cercano al tiempo real a través de cientos de años luz de espacio.

Quizás, mientras navegan alrededor de las galaxias, las civilizaciones extraterrestres avanzadas emiten algunas ondas de radio en el proceso. Nuestras antenas podrían eventualmente detectarlas. ¿Pero equivaldrían a señales? ¿Seríamos capaces de tomar nota de ellos como signos de inteligencia? Considere si el ruido producido por una lavadora constituye una señal, un signo de comunicación inteligente por parte de los humanos. Realmente no. Los humanos que intentan detectar mensajes extraterrestres en sus ondas de radio desechadas podrían ser como hormigas súper inteligentes que intentan detectar formas de vida avanzadas utilizando su alta sensibilidad a las feromonas que permanecen en el suelo.

Desde la perspectiva de las hormigas, las hormigas están tan orgullosas de su sentido químico más sofisticado, que las feromonas son obviamente la mejor manera de comunicarse. Esta suposición no sería exactamente incorrecta. Muchas especies usan feromonas para todo tipo de "comunicación". No puede ser la base de un lenguaje genuino, ya que la transmisión y la recepción químicas no pueden lograr la precisión de los conceptos abstractos o la 
infinita variedad de posibles significados que puede lograr el intercambio auditivo o visual. La transmisión química es demasiado tosca y torpe para la sintaxis y la gramática. Pero estas hormigas súper inteligentes podrían suponer correctamente que incluso las formas de vida muy avanzadas seguirán usando feromonas. Los humanos lo hacen, después de todo. Las feromonas pueden indicar de forma silenciosa, pero eficaz, todo tipo de cosas interesantes, como excitación sexual o agresividad. Quizás las feromonas humanas podrían ser detectadas en el suelo por hormigas súper inteligentes. ¿Podrían descifrar nuestras señales de feromonas? ¿Son nuestros olores malolientes algo así como mensajes para decodificar? Por analogía, la radio puede no ayudarnos a decidir que hemos detectado extraterrestres inteligentes.

Cuando la mayoría de la gente piensa en el Primer Contacto con extraterrestres, lo primero que le viene a la mente es probablemente algo así como Encuentros cercanos del tercer tipo de Steven Spielberg o Contacto de Carl Sagan. Spielberg tomó prestado el título de su película de 1977 de J. Allen Hynek. Hynek ayudó al Proyecto Bluebook de la Fuerza Aérea de los EE. UU., la investigación oficial del gobierno sobre los ovnis durante las décadas de 1950 y 1960. Propuso un sistema de clasificación de primer, segundo y tercer tipo de supuestos encuentros extraterrestres, desde avistamientos distantes de naves espaciales hasta ver extraterrestres de cerca. Durante una era fascinada por numerosos relatos de avistamientos $y$ abducciones extraterrestres, Encuentros cercanos del tercer tipo tocó la fibra sensible con un público medio persuadido de que los extraterrestres ya estaban merodeando por la Tierra. Menos mal que nada de esta histeria resultó ser verificable. De 1969 a 1991, la ley federal de los EE. UU. penalizó cualquier contacto con extraterrestres (no, no lo inventé).

El escenario de contacto de Sagan comienza con la decodificación de comunicaciones extraterrestres grabadas por antenas de radio gigantes y culmina con conversaciones humanas con extraterrestres. EI libro de Sagan de 1985 fue, por supuesto, un ejercicio poético de realización de deseos. Cabildeó vigorosamente para que se financiaran los proyectos SETI, y con frecuencia predijo el éxito durante su propia vida. Entre los científicos que piensan que es posible e importante detectar civilizaciones alienígenas, existe un apoyo modesto para los proyectos SETI de varios tipos. Por supuesto, dado que nuestros telescopios ligeros no han encontrado ninguna evidencia de actividad extraterrestre (avistamientos de vastos sitios de construcción del tamaño del sistema solar, estrellas explotadas al azar o rayos sospechosos de alta energía), no tenemos nada más, además de la radio, para usar en este momento. Por lo que sabemos, la transmisión de extraterrestres podría estar usando láseres súper avanzados, o neutrinos, o quién sabe qué, que aún permanecen fuera de nuestro alcance tecnológico.

Los proyectos SETI, hasta hace muy poco, solo sintonizaban frecuencias de radio que son fáciles de escuchar en la Tierra, porque ni las estrellas ni nuestro propio ruido las ahogan. Estas frecuencias no serían demasiado prácticas para las comunicaciones planetarias ordinarias, pero serían ideales para balizas de larga distancia que solo digan "¡Estamos aquí!" SETI se basó originalmente en la noción de que una civilización alienígena querría anunciar claramente su presencia al resto de la galaxia. Es por eso que el hecho de que SETI no detecte señales de radio o televisión de los sistemas estelares del vecindario no significa mucho todavía. Todavía podría haber mucha vida inteligente a nuestro alrededor. Dado que las civilizaciones a medida que avanzan no emitirán señales utilizando radiación electromagnética mucho o durante mucho tiempo, y dado que probablemente hay formas más eficientes de llamar la atención sobre uno mismo que los fotones, SETI tendría pocas posibilidades de éxito de todos modos. Sin embargo, si los extraterrestres se vuelven más inteligentes que nosotros, deberían darse cuenta de que, en primer lugar, simplemente gritar a través de las galaxias es bastante tonto. ¿Cómo vas a hacer amigos de esa manera? ¿Y no estarías simplemente colgando un letrero de "Ven y come" en tu casa planetaria para extraterrestres más grandes y hambrientos? Los Transformers no son todos ángeles, recuerda.

Quizás en otros cien años, con una capacidad de recepción mejorada para escuchar a escondidas en todos los planetas, en todas las frecuencias, dentro de una esfera de mil años luz de diámetro a nuestro alrededor, entonces los resultados de SETI, positivos o negativos, realmente ayudarán a calcular la distribución de civilizaciones inteligentes en nuestra galaxia. O eso esperan los científicos. Sin embargo, no todos los escritores de ciencia ficción han asumido que escuchar sobre civilizaciones alieníge- 
nas será una simple cuestión de construir una antena de radio aún más grande.

Algunas de las historias más sugerentes sobre el contacto exploran la posibilidad exactamente opuesta, que la comunicación con extraterrestres resulta ser muy difícil o imposible. La novela Solaris de Stanislaw Lem de 1961 relata el descubrimiento de un organismo del tamaño de un océano en un planeta distante que evidentemente es capaz de pensamiento inteligente, pero ningún concepto humano es adecuado para comprender esta peculiar forma de vida. En el universo alternativo de Transformers, los humanos no tienen problemas de comunicación con el idioma de los extraterrestres visitantes, porque los Transformers aprenden el nuestro. En la película Transformers de 2007, Optimus Prime le dice a Sam que adquirieron nuestro idioma de la World Wide Web. Esto tiene más sentido. Si se supone que los extraterrestres que llegan son mucho más avanzados, ¿no descubrirían nuestros idiomas antes de que nosotros descubramos los suyos?

Para que los extraterrestres aprendan nuestro idioma y se nos revelen, primero tendrían que encontrarnos, por supuesto. ¿No debería ser ese el escenario con más sentido? Las civilizaciones intergalácticas, que deambulan a altas velocidades (tal vez incluso a velocidades trans-lumínicas) durante largos períodos de tiempo (tal vez durante miles o millones de años), presumiblemente llegarían primero a la Tierra. Al menos deberían poder interceptar nuestras señales primitivas mientras pasan cerca de alguna carretera interestelar. Incluso si dejaron de usar la radio para sus propias comunicaciones hace mucho tiempo, podrían programar fácilmente uno de sus sensores espaciales para captar automáticamente cualquier señal primitiva. Esto todavía supone que los alienígenas avanzados mantienen cierta curiosidad sobre las civilizaciones infantiles. Todavía nos preocupan las molestas plagas de hormigas.

Sin embargo, la carretera extraterrestre más próxima tendría que estar cerca de la Tierra; a unos ochenta años luz, de hecho, desde que las transmisiones de alta potencia escaparon de la Tierra por primera vez en la década de 1930. Dado que los satélites, cables y Wi-Fi están reemplazando rápidamente la transmisión de antenas de alta potencia incluso ahora, la Tierra pronto volverá a estar bastante silenciosa. Solo los elementos ruidosos, pero tontos, como los radares militares, seguirán transmitiendo al espacio, pero no hay ningún mensaje allí. Nuestro centelleante destello de deportes, noticias y entretenimiento seguirá avanzando hacia el espacio, como una capa de humo exuberante que se expande y significa el fuego de la vida inteligente para cualquiera que todavía se moleste en escuchar esas frecuencias. Quizás dentro de un millón de años, algún receptor extraterrestre notará la señal de humo primitiva de nuestra especie y se preguntará si sus emisores todavía están vivos. De manera similar, eventualmente podríamos captar transmisiones primitivas de una civilización alienígena desaparecida hace mucho tiempo en el otro lado de la galaxia, si somos lo suficientemente pacientes. Ese es un escenario más probable, en realidad, que sintonizar una civilización cercana. De hecho, decepcionantemente realista. Finalmente escuchamos de ellos, pero no a tiempo para invitarlos a tomar el té.

\section{Derribando}

Hasta ahora, la ciencia y la lógica común nos advierten que la radio no es un medio inteligente de Primer Contacto. Lo que realmente queremos es un encuentro cercano del tercer tipo, de todos modos. ¡Entonces deberían venir a nosotros! ¿Por qué no están aquí ya? ¿Dónde están los extraterrestres? Esa es una muy buena pregunta. Es una pregunta tan buena que se ha utilizado en argumentos que concluyen que no existen otras civilizaciones galácticas avanzadas en este momento. Si lo hicieran, entonces ya habrían llegado aquí; pero no están aquí, por lo que no existen.

Ahora, este argumento de derribo contra los extraterrestres se basa en ciertas premisas adicionales. Primero, tendrías que asumir que los extraterrestres querrían explorar esta galaxia a fondo. En segundo lugar, tendrías que pensar que sería bastante fácil para los extraterrestres llegar aquí. En tercer lugar, tendrías que descartar la posibilidad de que ya hayan estado aquí, o tal vez que estén aquí ahora mismo, iiDISFRAZADOS!! En cuarto lugar, tendrías que adivinar que los extraterrestres visitantes, si ya están aquí, son bastante benignos y poco agresivos, ya que aún no hemos sido devorados ni esclavizados. En otras palabras, no vamos a quedar atrapados en algo como Battleground Earth de L. Ronald Hubbard o la película Independence Day de 1996. (Por otro lado, los extraterrestres entrantes podrían ser simplemente burócratas indiferentes que intentan 
demoler la Tierra, como los poéticos Vogons en Hichhikers 'Guide to the Galaxy de Douglas Adams). Resumiendo, se necesitan cuatro suposiciones principales para que este argumento contra los extraterrestres funcione. El éxito significa que no hay extraterrestres en absoluto y ningún escenario de Transformers para el primer contacto, nunca.

Afortunadamente para los defensores del escenario de Transformers como yo, las cuatro premisas de este argumento probablemente estén equivocadas. No podríamos descartar a los extraterrestres de esta manera. De hecho, a medida que cuestionamos estas cuatro suposiciones, iel escenario de Transformers en realidad se vuelve más plausible! Comencemos con la tonta noción de que las civilizaciones avanzadas desean sinceramente llegar a nosotros. En el escenario de Transformers, nuestros heroicos extraterrestres no tienen ninguna razón para jugar con formas de vida tan primitivas como nosotros. No tenemos tecnologías ni fuentes de energía impresionantes, y los Transformers no necesitan mucho oxígeno o planetas ricos en agua para habitarlos. La mayoría de las civilizaciones alienígenas capaces de viajes intergalácticos probablemente se parezcan más a los Transformers en este sentido. Para nosotros, pensar que los extraterrestres avanzados están vitalmente interesados en planetas como la Tierra es como hormigas súper inteligentes imaginando que los humanos estamos obsesionados con encontrar grandes hormigueros a los que movernos directamente.

\section{Bastante tonto}

En cambio, lo que realmente preocupa a nuestra imaginación humana es este escenario más oscuro. Una civilización alienígena un poco más avanzada, capaz de moverse torpemente alrededor de los sistemas estelares cercanos, quiere encontrar más Tierras para colonizar y explotar. Este es el escenario de Star Trek. Por cada buena civilización vulcana en nuestro rincón de la galaxia, ¿cuántas desagradables civilizaciones Klingon y Romulanas podría haber? En otras palabras, comenzamos a imaginar el mismo escenario básico cuando los exploradores europeos se toparon con América del Norte hace cuatrocientos años y se preguntaron cómo lidiar con los nativos americanos, mientras que los nativos americanos se preguntaban cómo ponerse al día con las tecnologías europeas. En realidad, los extraterrestres que nos mantienen despiertos por la noche somos solo nosotros disfrazados, con mayores tecnologías pero la misma ética. No ángeles, sino demonios.

Sin embargo, a menos que sea realmente fácil para la vida inteligente surgir en muchos tipos de sistemas estelares, probablemente no haya una civilización un poco más avanzada cerca en este momento. De hecho, es posible que actualmente no tengamos ninguna civilización avanzada en nuestro vecindario local. Incluso si la galaxia de la Vía Láctea ha estado generando una civilización avanzada capaz de viajar galácticamente a la velocidad de una vez cada millón de años durante los últimos mil millones de años, solo estamos hablando de mil civilizaciones que han tenido la oportunidad de tropezar con la Tierra durante ese vasto lapso de tiempo. ¿Es realmente tan fácil para los extraterrestres descubrirnos? La galaxia es bastante grande (cien mil años luz de diámetro y tres mil años luz de espesor), imponentemente grande incluso para extraterrestres con motores más rápidos que la luz. Supongamos que cada civilización dura alrededor de un millón de años antes de que expire o evolucione tanto que trascienda las pequeñas preocupaciones galácticas (esa es una duración bastante optimista, pero sigamos adelante). Las probabilidades precisas de que cualquiera de estas mil civilizaciones corra por la Tierra ahora, justo cuando el Homo sapiens se ha expuesto de manera destellante para que todos lo vean, resulta ser bastante pequeñas. El hecho de que no estén aquí en este momento no significa que todavía no estén ahí afuera.

Claro, los científicos quedan cautivados por la hipótesis de que una civilización de rápido crecimiento podría colonizar prácticamente toda la galaxia en un millón de años, más o menos, por sí sola. Bueno, dado que nadie ha logrado ya una colonización tan invasora aquí en la Tierra, podemos descartar esa hipótesis, y eso nos dice algo. Nos dice que es realmente difícil colonizar toda una galaxia, o que las civilizaciones en expansión, tarde o temprano, quieren hacer otra cosa, como disfrutar de la dicha de entrar en el estado de energía pura, o algo exaltado por el estilo. El hecho de que los humanos seamos obsesivamente compulsivos con la expansión reproductiva no significa que todos los demás también lo sean.

Las probabilidades de que los extraterrestres o sus sondas robóticas hayan examinado la Tierra en el pasado, notando océanos llenos de peces y trilobi- 
tes hace cuatrocientos millones de años, o tal vez mapeando inmensos pantanos repletos de dinosaurios hace cien millones de años, son algo mayores. La historia de los dibujos animados y los cómics de los años 80 cuenta cómo los Transformers se estrellaron contra un volcán de la Tierra hace cuatro millones de años. Solo la película de 2007 lanza el Primer Contacto de Transformers a la época contemporánea, ya que el Capitán Archibald Witwicky descubre el Megatron congelado en el Círculo Polar Ártico, en el lugar del accidente que data de hace solo unos pocos siglos. La película de 2007 satisface más los prejuicios de la audiencia y se ajusta menos a las expectativas científicas razonables.

De todos modos, el escenario de Transformers en general no asume precipitadamente que la civilización de los Transformers busca activamente planetas similares a la Tierra, o se preocupa mucho por descubrir sociedades primitivas en esos planetas. De hecho, el escenario de Transformers también altera la tercera suposición común detrás de toda esta preocupación por el Primer Contacto: que incluso podríamos saber si los extraterrestres han estado aquí. Cualquier visita extraterrestre a la Tierra en el pasado profundo probablemente no dejó rastro, a menos que se dejaran deliberadamente artefactos para influir en la evolución o para darnos algo que descubrir (este es el escenario de Stanley Kubrick y Arthur C. Clarke en su película de 1968 2001: A Space Odisea). Y como no vemos ningún extraterrestre ahora, cualquier extraterrestre actualmente en la Tierra tendría que tener un disfraz considerablemente bueno, especialmente si están tratando de hacerse pasar por personas.

Esta fantasía paranoica de que un amigo o vecino es realmente un extraterrestre ha sido durante mucho tiempo el alimento de muchas películas de clase B y algunas series de televisión mediocres (¿recuerdas Mi marciano favorito o los alienígenas reptiles de V?), Así como la inspiración para algunos clásicos excelentes (como como la invasión de Body Snatchers y Men in Black). Sin lugar a dudas, los extraterrestres lo suficientemente inteligentes como para llegar aquí probablemente podrían descubrir cómo parecerse a nosotros de alguna manera. Pero, ¿podrían comportarse y hablar con la misma facilidad que nosotros? Claro, podrían aprender nuestros idiomas e incluso penetrar en nuestras mentes. Pero pasar la prueba de Turing es otro asunto completamente diferente. Construir nuestras propias computadoras capaces de mantener conversaciones normales en todas las circunstancias diarias, de manera tan convincente que la gente no pueda notar ninguna diferencia, parece ser tremendamente difícil, y ya entendemos nuestra propia psicología, idioma y cultura. Pasar como humano presentaría un enorme desafío para una raza alienígena muy avanzada, incluso si esa raza alienígena quisiera molestarse con tal esfuerzo.

\section{Adaptándose}

Si los extraterrestres quisieran observarnos de cerca y en persona, sin tener que hablar con nosotros (y difícilmente podría culpar a los extraterrestres si la mayoría de las conversaciones humanas los aburriera de sus exoesqueletos extraterrestres), ¿no sería más fácil conseguir algún otro tipo de disfraz además de un cuerpo humano? El mejor disfraz sería la invisibilidad total, pero incluso la invisibilidad no es suficiente, ya que tomarían algo de volumen y desplazarían otras cosas de todos modos. Para un contacto cercano, esconderse al aire libre podría tener más sentido. Podrían disfrazarse de árboles, bonitos arbustos o hermosas petunias. Si los extraterrestres están hechos de moléculas orgánicas como nosotros, tal vez puedan cambiar de forma a otros organismos. En realidad, si necesitan conocer de cerca y en persona de forma regular, ¿qué pasa con los disfraces de máquinas?

Mmm . ..., podría haber serias ventajas para una estrategia de disfraz no orgánica. Un alienígena disfrazado de máquina no tendría que preocuparse por ser cortado, cortado o devorado. Los pinos que se escabullan o los dientes de león que se estremecen se notarían después de un tiempo. Pero, ¿qué pasa con una máquina? Siempre que un alienígena disfrazado de máquina pareciera correcto e hiciera lo que se suponía que debía hacer, podría engañarnos fácilmente, como conducir un Chevy Camaro como el Autobot Bumblebee o reproducir música como un boombox como el Decepticon Frenzy. Una forma de máquina útil podría ser tan grande como un edificio de apartamentos completo, o tan pequeña como un diminuto nanobot del tamaño de una pulga. Los Autobots no han elegido una forma tonta al seleccionar nuestros vehículos, ya que pueden tener una fácil movilidad. Apenas prestamos atención a los automóviles o aviones cuando se desplazan a toda velocidad, siempre que se sigan los patrones de tráfico convencionales. De 
todos modos, supongo que cuanto más pequeño mejor. Sigo encontrando y perdiendo mi reloj, ahora que lo pienso.

Mientras reflexionamos sobre el tipo ideal de disfraz extraterrestre, deberíamos cuestionarnos seriamente si un extraterrestre visitante sería necesariamente orgánico en primer lugar. Hay muchas buenas razones para pensar que, si hay vida en la galaxia, entonces evolucionó a partir de moléculas orgánicas simples compuestas de hidrógeno, carbono, oxígeno y nitrógeno. Pero independientemente de qué compuestos orgánicos sean la forma más fácil de comenzar la vida, aquí debemos reflexionar sobre una pregunta muy diferente. ¿Una civilización alienígena altamente avanzada, con suficiente tecnología y longevidad para llegar a nosotros primero, seguiría siendo en su mayoría orgánica?

Tal vez el Primer Contacto sea con extraterrestres metálicos duros, no extraterrestres suaves y blandos. Seth Shostak ha estado proclamando públicamente que el Primer Contacto probablemente será con una civilización completamente robótica que posea cerebros de computadora cargados con programación de Inteligencia Artificial (IA). Shostak es astrónomo sénior en el Instituto SETI en Mountain View, California, y un destacado conferencista sobre los temas de la vida extraterrestre y el primer contacto. Su predicción se basa en la suposición razonable de que las civilizaciones muy avanzadas y longevas dependerán en gran medida de las tecnologías mecánicas y de computación para superar las limitaciones y debilidades inherentes de los cuerpos orgánicos y los cerebros neuronales. Si alguna civilización se acerca a la inmortalidad, argumenta, entonces se habrá transformado en robots de inteligencia artificial.

Aunque este razonamiento es persuasivo, es todavía bastante especulativo (¿orgánico o metálico son las únicas alternativas para la vida?). La visión de Shostak provoca otro experimento mental. Quizás el Primer Contacto no sería directamente con una raza alienígena, sino más bien con emisarios robóticos con IA de una raza alienígena. Enviar sondas robóticas, especialmente robots de razonamiento y autorreplicación, proporcionaría una exploración mucho más eficiente, si lo que se desea es una gran cantidad de datos de toda la galaxia lo más rápido posible. Si una sonda nos alcanza y viene equipada con su propia IA para una conversación inteligente, entonces nuestro Primer Contacto sería con el portavoz de una raza alienígena.

De hecho, siguiendo este escenario hasta su conclusión lógica, podríamos encontrarnos con una sonda robótica, pero nunca hablar con su amo. En cierto modo, esta posibilidad todavía rastrea aproximadamente el escenario de Transformers, ya que los Transformers fueron creados, según la serie de televisión, como esclavos robóticos de una raza maestra llamada Quintessons. Si las sondas tardan mucho en llegar a nosotros, especialmente si la raza constructora se originó en un cuadrante diferente de la galaxia, entonces no hay garantía de que los constructores sigan existiendo, y mucho menos de que se preocupen por comunicarse directamente. Tal vez las sondas robóticas estén programadas para esta posibilidad, anunciando mensajes de la raza maestra alienígena que nunca podrían entregarse personalmente. El mensaje de una sonda podría equivaler a: "Para cuando escuche esto, estaremos muertos. .. " Y una sonda podría haber desarrollado por sí misma su propia agenda, quizás su propia autonomía. ¿Podrían las sondas alienígenas, originalmente programadas con buenas intenciones, volverse malévolas? ¿Es eso tan improbable? Pregúntale al Capitán Kirk, quien se enfrentó al misteriosamente poderoso V'ger que invade nuestro sistema solar solo para descubrir nuestra propia nave Voyager en su corazón, en la primera película de Star Trek.

\section{Chocándonos}

Hay muy pocas razones, si seguimos pensando en ello, para seguir suponiendo que nuestro Primer Contacto será directamente con una raza alienígena benévola y pacífica que se parezca a nosotros y que esté muy feliz de conocernos. El escenario de Transformer, o algo bastante similar, está aumentando en probabilidad relativa frente a las alternativas. Avancemos.

Ahora hemos llegado a la cuarta suposición necesaria, que un extraterrestre disfrazado en la Tierra sería benigno y pacífico, para afianzar el gran argumento de que realmente no existen extraterrestres. Al principio, esta suposición parece plausible. Después de todo, si están disfrazados, entonces no se están exhibiendo, lo que aterrorizaría o desmoralizaría a la población humana. Solo los alienígenas conquistadores mostrarían su verdadera y aterradora forma. ¿Pero 
no suena esto como pensamiento ilusorio, solo otra versión de la fantasía de "los alienígenas avanzados son ángeles"? Mientras operamos en ese nivel mitológico, recuerde algo de la mitología religiosa básica: generalmente son los demonios, y no los ángeles, quienes son maestros en la astucia, el engaño y el embuste.

Consideremos lo que está sucediendo en el escenario de Transformers. La razón principal por la que la raza de los Transformers adopta el disfraz de cualquier mecánica que haya por ahí tiene poco que ver con las especies nativas locales. El objetivo del disfraz transformador es completamente militar, para obtener una ventaja sobre el enemigo. Los Autobots y los Decepticons están atrapados en una terrible guerra civil que ha estado sucediendo durante muchos milenios. Desde el comienzo de la guerra civil, han desarrollado sus tecnologías increíblemente avanzadas durante ese tiempo, principalmente para ganar esta guerra. En el segundo episodio de televisión, Spike le pregunta a Trailbreaker por qué los Autobots se transforman y Trailbreaker responde: "Simple. ¡Ocultar! Además, seguro que es mejor que caminar ". En un episodio posterior de la tercera temporada, se explica que la transformación fue una invención tecnológica de los Autobots para usar en contra de los Decepticons, quienes pronto duplicaron esta habilidad por sí mismos.

Los visitantes extraterrestres no solo pueden usar el disfraz para sus propios fines en lugar de para cualquier cosa que tenga que ver con nuestra preocupación, no podemos suponer que los visitantes extraterrestres sean capaces de preocuparse por otras especies. Hay una curiosa contradicción intrínseca en la caracterización de los Transformers. Por un lado, tenemos el cartel de la película de dibujos animados de 1986, The Transformers: The Movie, que incluye el siniestro titular: Beyond Good. Beyond Evil. Beyond Your Wildest Imagination. ¿De qué manera podrían los Transformers estar más allá del bien y del mal? Tal vez porque sus preocupaciones trascienden tan completamente las nuestras que no pudimos juzgarlos por nuestros estándares humanos de moralidad. Por otro lado, gran parte de la serie de dibujos animados y cómics se basa en un grado de bondad atribuido a los Autobots. Muchos Autobots desarrollan relaciones positivas e incluso protectoras con algunos humanos. La película de 2007 va más lejos en esta dirección. Optimus Prime pronuncia un principio ético, algo parecido a la Primera Directiva de Star Trek, en el sentido de que cada especie debería tener la libertad de desarrollarse a su manera. Optimus Prime incluso está dispuesto a suicidarse si eso pone fin a la guerra en la Tierra. Al final de la película, los Autobots asumen una postura protectora sobre la Tierra y sus habitantes humanos. Esta beneficencia contrasta marcadamente con el malvado desdén del Decepticon hacia los humanos a lo largo de los dibujos animados, los cómics y las películas. En conjunto, la raza de los Transformers no se preocupa por nosotros, aunque algunos Autobots lo intentan. Este patrón puede ser común entre civilizaciones alienígenas avanzadas.

Sin embargo, puede ser decepcionante que los Transformers sean tan militaristas y estén empeñados en la guerra total. ¿Qué tan realista es ese aspecto del escenario de Transformers? Si escuchamos a los científicos que favorecen la hipótesis de que las civilizaciones muy avanzadas deambulan por la galaxia en paz y tranquilidad, nos daríamos cuenta de que la guerra es tan primitiva y destructiva para todas las especies que el avance es igual a la pacificación. Pero esta noción probablemente también esté equivocada. Definitivamente no es consistente con lo que sabemos sobre la evolución cultural de nuestra propia especie. ¡Rápido, mencione la mayor fuente de inspiración tecnológica para los humanos durante los últimos doscientos mil años! Bien, la respuesta correcta es la búsqueda de suficiente comida. Caza, agricultura, procesamiento y almacenamiento de alimentos. Bueno, entonces, ¿cuál ha sido el segundo impulso más influyente detrás de la innovación tecnológica? Eso es correcto, la guerra. Tribus de humanos luchando, conquistando y esclavizando a otros humanos. ¿Cómo los patéticos europeos de finales de la Edad Media (digamos, 1000 d.C.), tan atrás de varias otras civilizaciones de esa época, aceleraron y dominaron todo el planeta solo ochocientos años después? Muchos historiadores ahora atribuyen un éxito tan asombroso a la intensa competencia militar entre las naciones europeas durante ese período.

La guerra probablemente también sea una de las principales fuerzas impulsoras de la evolución de cualquier otra civilización. El majestuoso relato de Arnold Toynbee de todas las civilizaciones humanas en los diez volúmenes de Un estudio de la historia (1934-1961) incluso eleva la guerra al estado supre- 
mo, necesario para explicar el curso de la desintegración interna de una civilización y su eventual destrucción, que proporciona materiales esenciales para las civilizaciones sucesoras. A menos que la especie humana en su conjunto sea peculiarmente perversa, podrida en su núcleo, otras especies exóticas probablemente atraviesen fases de guerra considerablemente largas, especialmente en los primeros milenios. La verdadera pregunta es si la guerra es compatible con la supervivencia a muy largo plazo. ¿Podría sobrevivir la guerra en toda la galaxia?

Se ha argumentado que incluso si la guerra es importante por un tiempo, en algún momento del progreso de cualquier civilización, todas las guerras deben cesar. Después de todo, la invención de armas nucleares, capaces de destrucción planetaria, parece dictar que una especie superviviente es una especie pacífica. Los vulcanos de Star Trek renunciaron a la violencia e incluso a todas las emociones, para evitar su extinción por sus propias manos. Sin embargo, ¿toda esta preocupación por la aniquilación nuclear se debe simplemente al hecho temporal de que actualmente estamos atrapados en un solo planeta? Si nuestra civilización comienza a colonizar otros planetas y el espacio profundo dentro de los próximos diez mil años, el destino de toda la especie ya no dependerá de una sola bola redonda de roca. Especies inteligentes como la nuestra, que alcanzan esta etapa más peligrosa, este preocupante cuello de botella del desarrollo, deben pasar esta prueba. ¿Pueden estas especies resistir el suicidio mediante la guerra? Si es así, entonces la recompensa es una expansión potencialmente infinita a través de esta galaxia y tal vez también otras galaxias. Sin embargo, después de que una especie atraviesa con éxito el cuello de botella planetario, es fácil imaginar que la guerra volverá a surgir.

De hecho, si la guerra es tan devastadoramente efectiva para inspirar un rápido desarrollo tecnológico, podemos inferir que cualquier raza muy avanzada probablemente habrá seguido su fase temporalmente pacífica con fases bélicas aún más intensas. $Y$ si hay varias civilizaciones avanzadas que participan en una interacción competitiva, es posible que tengan todos los incentivos para recurrir a la guerra. Hasta que una civilización esté tan avanzada que ni la energía ni la muerte sean un problema, la guerra es una solución. Sin embargo, las civilizaciones más allá de la energía y de la muerte no estarán demasiado interesadas en nosotros, más de lo que nos gustaría tener intimidad con organismos similares a bacterias en otros planetas.

Las civilizaciones avanzadas que deambulan por la galaxia probablemente todavía sepan todo sobre la guerra. Tampoco debemos suponer que las civilizaciones avanzadas tendrán religiones avanzadas que ayudarán a mantener la paz. Las religiones humanas son notoriamente flexibles sobre la guerra. Incluso los Transformers tienen una especie de religión, según los cómics, pero no es una gran sorpresa. Los dioses primordiales Unicron y Primus luchan por la supremacía sobre el universo y Primus crea a Cybertron y a los Transformers en el camino para ayudar en la lucha (recordando la antigua religión persa del zoroastrismo). También parece obvio que una verdadera civilización militarista tendría una religión realmente militarista. Hemos analizado un argumento radical contra los extraterrestres y hemos refutado todas las premisas. Debemos seguir anticipando que el Primer Contacto eventualmente ocurrirá. El Primer Contacto probablemente será con una civilización en expansión más adelantada que nosotros, pero no tan lejos como para ser completamente indiferente para nosotros. Es posible que no nos estén buscando y que el Primer Contacto les sorprenda tanto como a nosotros. No serán ángeles, sino que estarán simplemente absortos en sus propias preocupaciones y conflictos. Con suerte, algunos de ellos tienen suficiente bondad para evitar que nos aniquilen. En otras palabras, estamos armando algo similar al escenario de Transformers.

Cuando reflexionamos sobre cómo será el Primer Contacto, con demasiada frecuencia proyectamos nuestras propias mitologías, fantasías, preocupaciones e incluso nuestras propias psicologías sobre hipotéticas civilizaciones alienígenas. Es comprensible que esperemos desesperadamente que razas alienígenas pacíficas y benévolas estén esperando y deseando ser contactadas por especies tan primitivas como la nuestra. Contemplamos la inmensidad del espacio, sintiéndonos vulnerables y asustados. Queremos ángeles y tememos a los demonios. Tarde o temprano, la especie humana tendrá que lidiar de manera realista con lo que sea y con quien sea que ya esté entre las estrellas. ¿Seguiremos desempeñando el papel de conquistadores hasta que nuestra conciencia culpable nos frene? 
¿Terminaremos en cambio como los aztecas, aniquilados por una potencia de fuego superior $y$ una enfermedad mortal?

Tal vez tememos en secreto un futuro aún más aterrador, en el que nunca conoceremos a nadie más y flotamos fríos y solitarios en medio de un universo en expansión que no va a ninguna parte. Queremos, y tememos, el Primer Contacto. A falta de encontrarse con Dios, este Primer Contacto ahora está impulsando la compulsión de la humanidad de mirar hacia el cielo. Nuestra imaginación evoca sueños y pesadillas. El escenario de Transformers es solo uno de muchos, y posiblemente uno profético.

Aún así, no nos sentimos listos, y no deberíamos, no importa cuánto tiempo miremos hacia arriba.

Hay más de lo que se ve a simple vista.

* La Sociedad Secular Humanista del Perú tiene el permiso expreso del autor para traducir y republicar el artículo publicado originalmente el año 2009 con el título de "First Contact" en el libro Transformers and Philosophy. More than meets the mind de la editorial Open Court.

**Artículo traducido por Piero Gayozzo para la revista Futuro Hoy del Fondo Editorial de la Sociedad Secular Humanista del Perú. Contacto: pgayozzo@ssh.org.pe

\section{Cómo citar este artículo:}

Shook, J. (2021). Contacto alienígena y transformers ¿el escenario más probable? Futuro Hoy, 2(3), 7-16. https://doi.org/10.52749/fh.v2i3.1. 